Fixed Point Theory, 18(2017), No. 2, 433-444

DOI 10.24193/fpt-ro.2017.2.34

http://www.math.ubbcluj.ro/ nodeacj/sfptcj.html

\title{
A NONLOCAL PROBLEM AT INFINITY FOR SECOND ORDER DIFFERENTIAL EQUATIONS
}

\author{
DAVID ARIZA-RUIZ*, CRISTÓBAL GONZÁLEZ** AND ANTONIO JIMÉNEZ-MELADO***
}

*Dept. Análisis Matemático, Fac. Matemáticas, Univ. Sevilla, Sevilla, Spain E-mail: dariza@us.es

** Dept. Análisis Matemático, Estadística e Investigación Operativa, y Matemática Aplicada, Fac. Ciencias, Univ. Málaga, 29071 Málaga, Spain

E-mail: cmge@uma.es

***Dept. Análisis Matemático, Estadística e Investigación Operativa, y Matemática Aplicada, Fac. Ciencias, Univ. Málaga, 29071 Málaga, Spain

E-mail: melado@uma.es

Abstract. In this paper we propose the study of a scalar integral equation of the type

$$
y(t)=g(y)+\int_{t}^{\infty}(s-t) a(s) f(y(s)) d s, \quad t \geq 0,
$$

and give conditions on $g, a$ and $f$ that ensure the existence of solutions on $[0, \infty)$ which are asymptotically equal to $g(y)$ at $\infty$. As a consequence, we obtain results on the existence of solutions for a problem of the type

$$
y^{\prime \prime}(t)=a(t) f(y(t)), \quad y(\infty)=g(y),
$$

where $y(\infty)=\lim _{t \rightarrow \infty} y(t)$. This problem could be thought as a sort of nonlocal problem at $\infty$, and our conditions on $f$ include the case of a linear equation.

Key Words and Phrases: Nonlocal problem, asymptotic behavior, integral equation, second order differential equation, Leray-Schauder type fixed point theorem.

2010 Mathematics Subject Classification: 34A34, 45M05, 47H10, 47N20.

\section{REFERENCES}

[1] R. P. Agarwal, M. Meehan, and D. O'Regan, Fixed Point Theory and Applications, Cambridge Tracts in Mathematics, vol. 141, Cambridge University Press, Cambridge, 2001.

[2] S. Aizicovici and H. Lee, Nonlinear nonlocal Cauchy problems in Banach spaces, Appl. Math. Lett., 18 (2005), no. 4, 401-407.

[3] F. V. Atkinson, On second order nonlinear oscillation, Pacific J. Math., 5 (1955), 643-647.

[4] R. Bellman, Stability Theory in Differential Equations, Dover Publications, Inc., New York, 1969.

Research partially supported by the Spanish (Grant MTM2012-34847-C02-01 for the first author, and Grant MTM2014-52865 for second and third authors) and regional Andalusian (Grants FQM127 and P08-FQM-03543 for the first author, and Grant FQM210 for second and third authors) Governments. 
[5] L. Byszewski and V. Lakshmikantham, Theorem about the existence and uniqueness of a solution of a nonlocal abstract Cauchy problem in a Banach space, Appl. Anal., 40 (1991), no. 1, 11-19.

[6] L. Byszewski and T. Winiarska, An abstract nonlocal second order evolution problem, Opuscula Math., 32 (2012), no. 1, 75-82.

[7] S. D. Dubé and A. B. Mingarelli, Note on a non-oscillation theorem of Atkinson, Electron. J. Diff. Equations, 2004 (2004), no. 22, 1-6.

[8] M. Ehrnström, Positive solutions for second-order nonlinear differential equations, Nonlinear Anal., 64 (2006), 1608-1620.

[9] M. Ehrnström, Linear asymptotic behaviour of second order ordinary differential equations, Glasgow Math. J., 49 (2007), 105-120.

[10] C. González and A. Jiménez-Melado, Existence of monotonic asymptotically constant solutions for second order differential equations, Glasgow Math. J., 49 (2007), 515-523.

[11] C. González and A. Jiménez-Melado, Asymptotic behavior of solutions to an integral equation underlying a second-order differential equation, Nonlinear Anal., 70 (2009), 822-829.

[12] E. Hille, Non-oscillation theorems, Trans. Amer. Math. Soc., 64 (1948), 234-252.

[13] S. Ji and S. Wen, Nonlocal Cauchy problem for impulsive differential equations in Banach spaces, Int. J. Nonlinear Sci., 10 (2010), no. 1, 88-95.

[14] T. Kusano and W. F. Trench, Global existence theorems for solutions of nonlinear differential equations with prescribed asymptotic behaviour, J. London Math. Soc., 31 (1985), no. 3, 478-486.

[15] J. W. Macki and J. S. W. Wong, Oscillation of solutions to second-order nonlinear differential equations, Pacific J. Math., 24 (1968), 111-117.

[16] O. G. Mustafa and Y. V. Rogovchenko, Global existence of solutions with prescribed asymptotic behavior for second-order nonlinear differential equations, Nonlinear Anal., 51 (2002), 339-368.

[17] E. Wahlén, Positive solutions of second-order differential equations, Nonlinear Anal., 58 (2004), $359-366$.

Received: October 13, 2014; Accepted: February 12, 2016. 